http://jmscr.igmpublication.org/home/ ISSN (e)-2347-176x ISSN (p) 2455-0450 crossref DOI: https://dx.doi.org/10.18535/jmscr/v8i4.37

\title{
Incidental detection of malrotated ectopic kidney on bone scintigraphy in a patient with thyroid carcinoma
}

Authors

\section{Mr. Adavala Jagadeesh, Dr Venkatesh Murthy K.S., Dr Harish, Dr Aisha, Mr. Nagaiah.H.J, Mrs. Rajini A.T, Mr. Mallikarjun, Ms. Shivamma}

Department of Nuclear Medicine, Kidwai Memorial Institute of Oncology, Bangalore 560029, India

\begin{abstract}
A 60-year-old male was suspected as a case of thyroid carcinoma. Tc ${ }^{99 m}$-methylene diphosphate bone scintigraphy was performed for the assessment of skeletal metastasis but showed no abnormal skeletal tracer uptake. However, planar images showed absent left kidney in its original renal fossa and right kidney was in normal shape, size and its position. There was an abnormal tracer uptake close to the right kidney anteriorly and it was mimicking as bone metastasis in the S4 vertebra.

Tc ${ }^{99 m}$ DTPA scan was performed two days later to prove suspected left ectopic kidney. Renal scan showed malrotaed ectopic left kidney just close to the right kidney and its function found to be normal.

Keywords: Bone Scintigraphy, Tc ${ }^{99 m}$ DTPA Renal scan, Duel Head Gamma camera, Malrotaed ectopic Kidney.
\end{abstract}

\section{Case History}

A 60 year male was suspected as a case of thyroid carcinoma and referred to nuclear medicine for evaluation of skeletal metastasis. Tc ${ }^{99 m}$ methylene diphosphonate bone scintigraphy was performed for the assessment of skeletal metastasis but showed no abnormal skeletal tracer uptake. However, planar images showed absent left kidney in its original renal fossa and right kidney was in normal shape, size and its position. (Figure.1).

His blood investigation showed normal serum creatinine value $1 \mathrm{mg} / \mathrm{dl}$. Two days later we performed $\mathrm{Tc}^{99 \mathrm{~m}}$ DTPA scan by Siemens duel head gamma camera acquired with both the detectors. Renal Flow images from anterior detector showed well perfused left ectopic kidney and normal right kidney as shown in Figure.2. GFR values of both the kidneys were calculated using gates protocal with anterior images and values found to be normal. (Figure.3)

Posterior images showed well perfused right kidney and faint tracer in the left ectopic kidney due to its anterior location. (Figure.4) 


\section{JMSCR Vol||08||Issue ||04||Page 191-194||April}

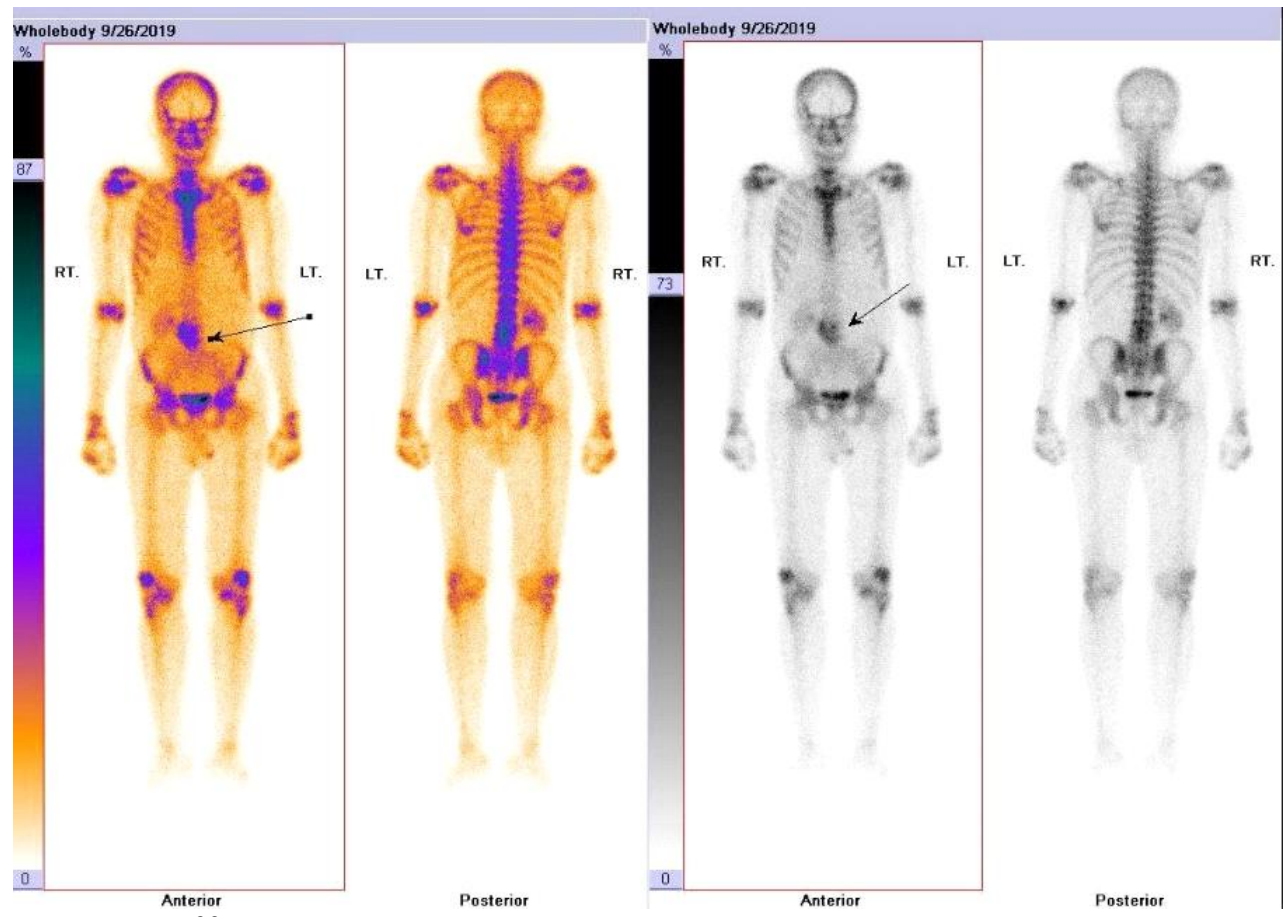

Figure 1: Whole body $\mathrm{Tc}^{99 \mathrm{~m}}$-methylene diphosphonate bone scintigraphy shows diffuse abnormal tracer activity superior to the pelvis (arrow). Rest of the skeleton is normal.

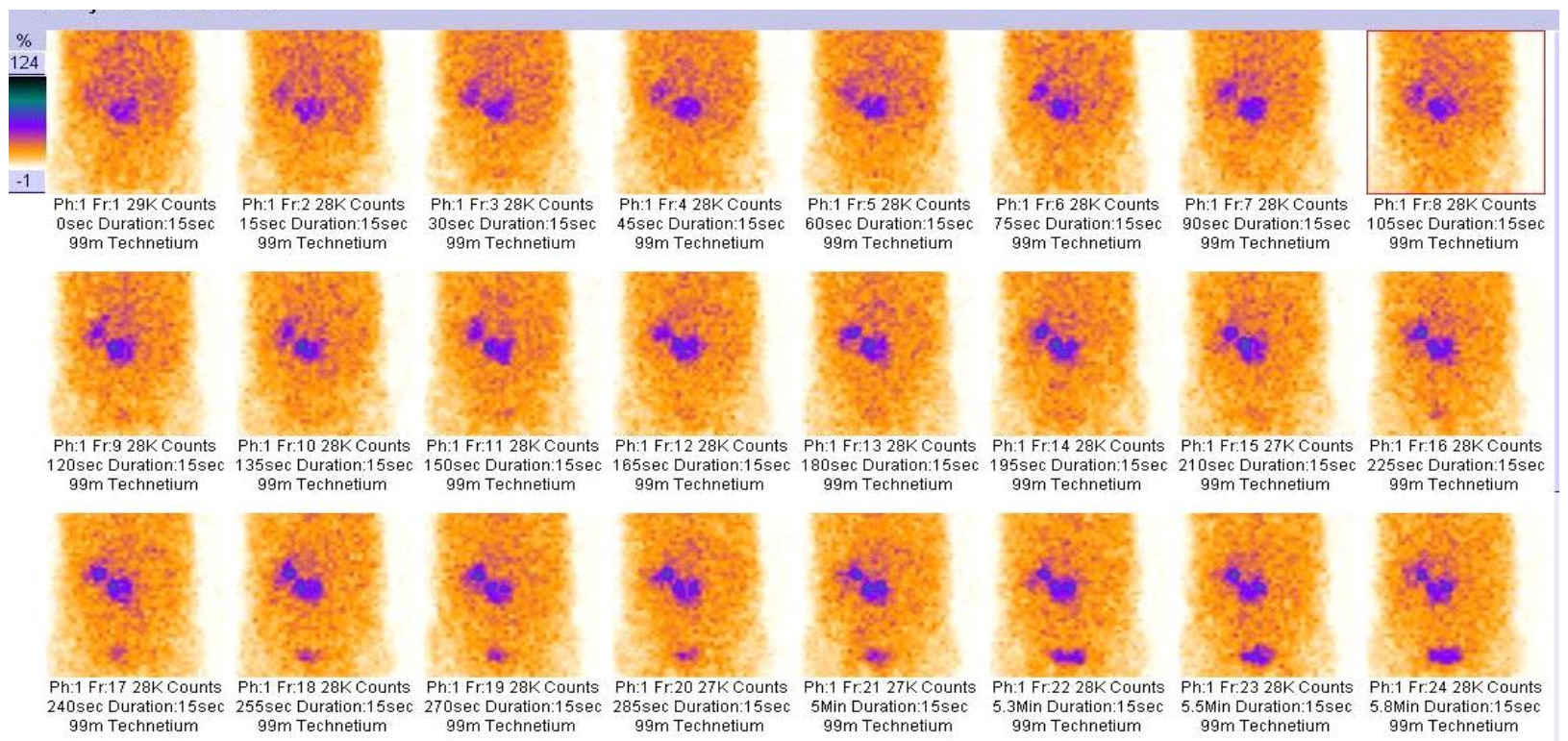

Figure 2: $\mathrm{Tc}^{99 \mathrm{~m}}$ DTPA Renogram flow images from anterior detector shows well perfused left ectopic kidney and normal right kidney. 


\section{JMSCR Vol||08||Issue||04||Page 191-194||April}

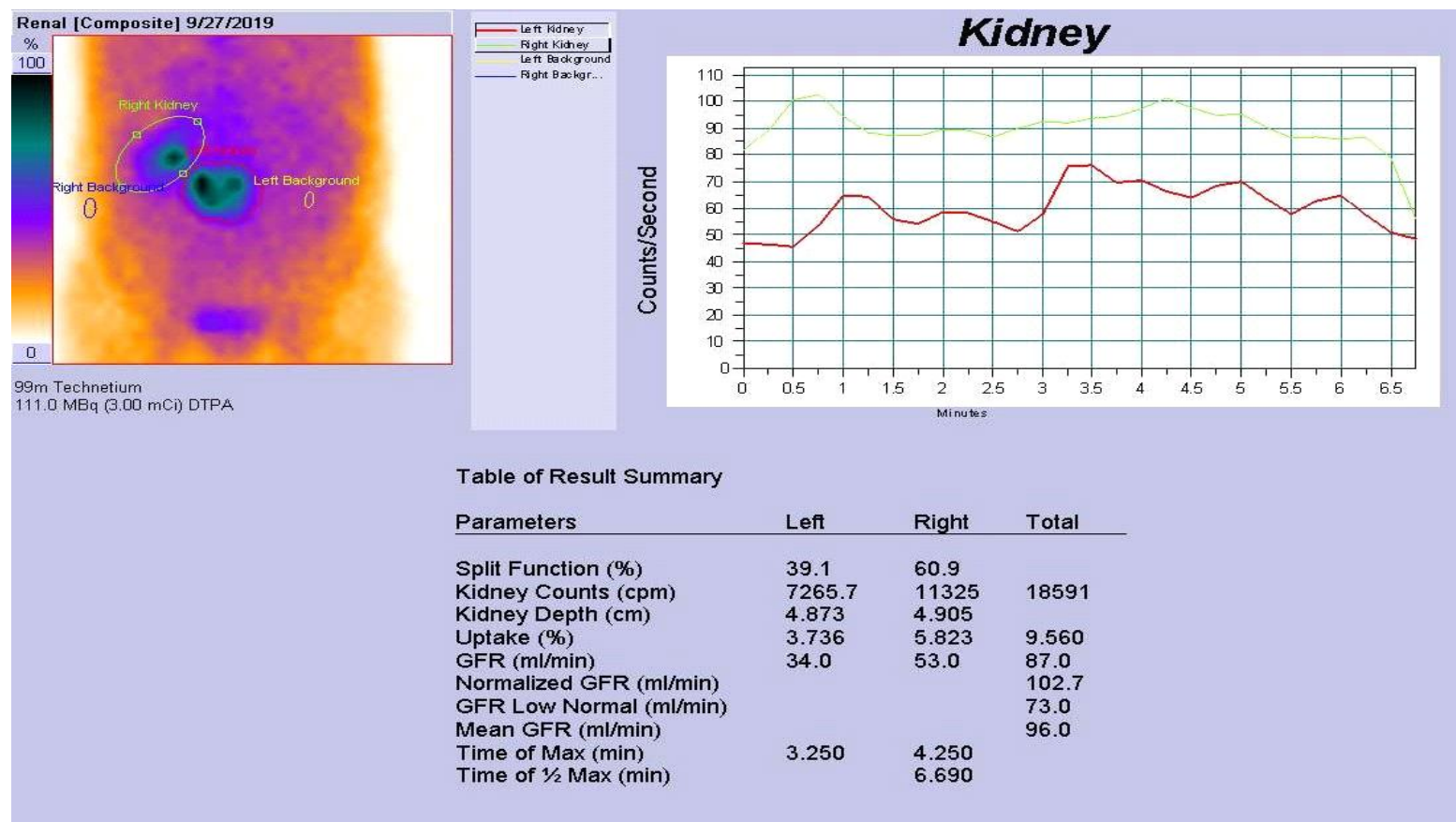

Figure 3: $\mathrm{Tc}^{99 \mathrm{~m}}$ DTPA Renogram GFR results from anterior detector shows normal function of kidneys.

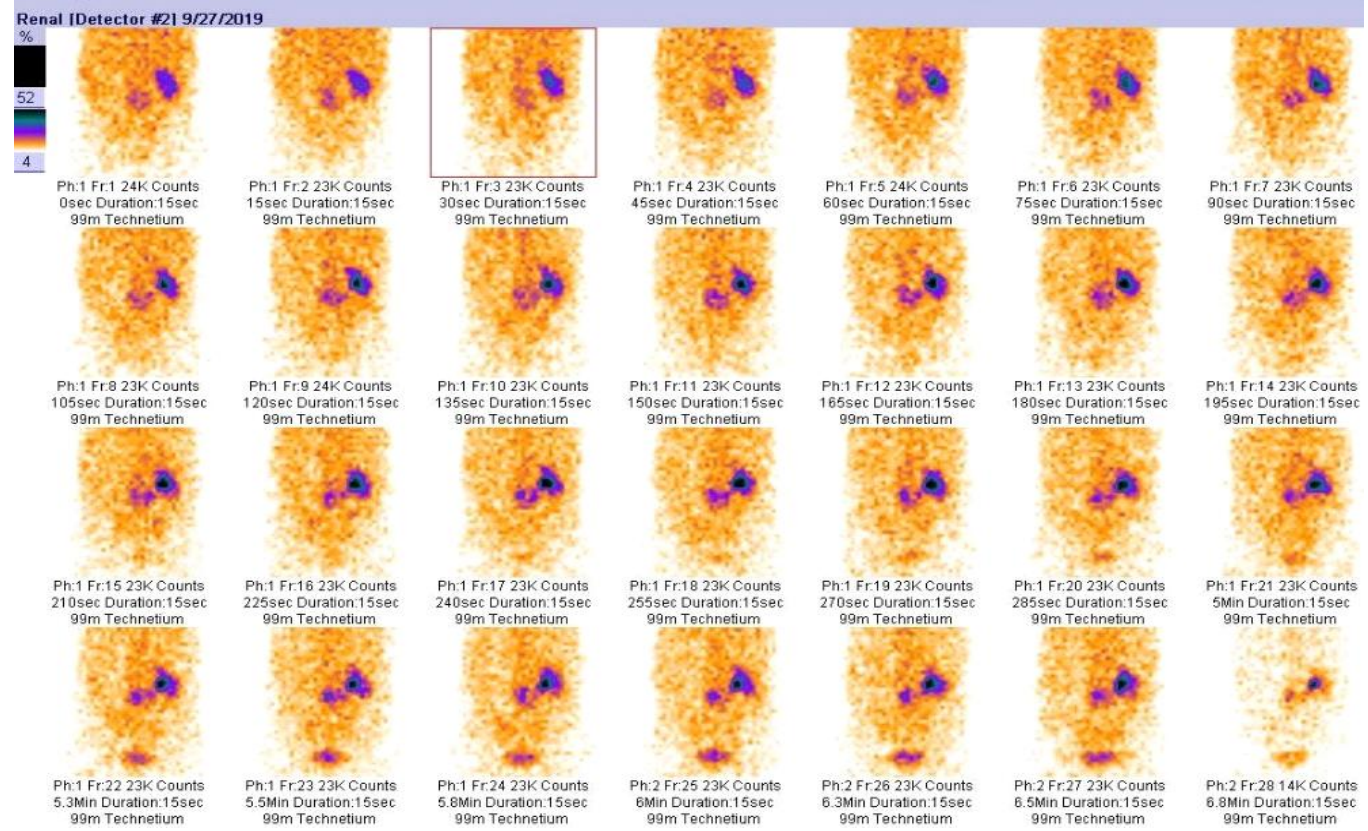

Figure 4: $\mathrm{Tc}^{99 \mathrm{~m}}$ DTPA Renogram Posterior flow images shows well perfused right kidney and faint tracer in the left ectopic kidney due to its anterior location.

\section{Discussion}

Ectopic kidneys are due to developmental abnormalities and may be located at the pelvic, iliac fossa or lumbar region, anywhere along the path of their usual ascent. If the kidney stays in the pelvic fossa during the ascending process, it is called as a pelvic kidney. This abnormality can be unilateral or bilateral. This incidence of ectopic pelvic kidney is reported as 1:2100 - 1:3000 in autopsy series $^{(1)}$. Ectopic kidneys are mostly asymptomatic. Hydronephrosis is seen in the half of the patients, due to malrotation of the kidney and anteriorly placed renal pelvis leading to impaired urinary drainage. ${ }^{(2)}$ Dual-head camera renography might be useful in daily practice with the potential to provide a better estimate of 
absolute function in each kidney and the relative kidney function in patients with differing kidney depths and/or malformed kidneys ${ }^{(3)}$.

In our study, the pelvic kidney was located close to the right kidney anteriorly and it was mimicking as bone metastasis as shown in fig. 1 .

Although ectopic kidney is a well-known finding, our case is a demonstrative example of malrotated ectopic kidney mimicking skeletal metastasis in MDP bone scan.

\section{Declaration of Patient Consent}

The authors certify that they have obtained all appropriate patient consent forms. In the form the patient(s) has/have given his/her/their consent for his/her/their images and other clinical information to be reported in the journal. The patients understand that their names and initials will not be published and due efforts will be made to conceal their identity, but anonymity cannot be guaranteed.

Financial support and sponsorship: Nil

Conflicts of Interest: There are no conflicts of interest.

\section{References}

1. Bauer SB. Anomalies of the upper urinary tract. In: Walsh PC, editor. Campbell's Urology. Philadelphia: wb Saunders: 2002.p. 1894.

2. Cinman NM, Okeke Z. Smith AD. Pelvic kidney: associated diseases and treatment. J Endourol. 2007; 21:836-842.

3. Madsen CJ1, Muller ML, Zerahn B, Fynbo C, Jensen JJ. Determination of kidney function with 99mTc-DTPA renography using a dual-head camera. Nucl Med Commun. 2013 Apr;34(4):322-7. 